\title{
A Novel Wood Adhesive Based on Yeast Hydrolysate
}

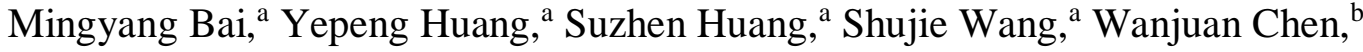 \\ Xianfeng $\mathrm{Hou},{ }^{\mathrm{a}, *}$ and Zhenzhong Gao ${ }^{\mathrm{a}, *}$
}

\begin{abstract}
Due to certain problems with petroleum-based products, the development of a renewable and green adhesive is urgent and important. Yeast hydrolysate, which contains more than $55 \%$ protein, possesses many advantages in its source (it originates from yeast as opposed to petroleum) and environmental protection. In this work, a wood adhesive based on yeast hydrolysate was developed through the addition of sodium dodecyl sulfate (SDS), polyvinyl alcohol, and ethylene glycol diglycidyl ether (EGDE) to improve properties of the yeast hydrolysate adhesive via the epoxy group in EGDE. The influence of EGDE on the adhesive properties (density, viscosity, solid content, bonding strength, and curing temperature) was investigated. The thermal property and changes in molecular structure during curing were characterized via differential scanning calorimetry and Fourier transform infrared spectroscopy, respectively. These results indicated that a ring-opening reaction between the epoxy group of EGDE and the active group had an important influence on the properties.
\end{abstract}

Keywords: Yeast hydrolysate; Wood adhesive; Ethylene glycol diglycidyl ether; Epoxy group

Contact information: a: College of Materials \& Energy, South China Agricultural University, Guangzhou 510642, P. R. China; $b$ : College of Materials Science and Energy Engineering, Foshan University, Foshan 528000, P. R. China; *Corresponding authors: xfhou@scau.edu.cn; zzgaoscau@163.com

\section{INTRODUCTION}

The wood-based panel industry has rapidly developed in recent decades. China's production of wood-based panels reached 315 million $\mathrm{m}^{3}$ in 2017. Accordingly, wood adhesive consumption exceeded 15 million tons. Moreover, formaldehyde-based adhesives, such as urea-formaldehyde (UF), phenol-formaldehyde (PF), and melamine-formaldehyde (MF) accounted for $80 \%$ to $90 \%$ of the total (Pradyawong et al. 2017). However, these petroleum-based products are facing varied problems due to a shortage of resources. In contrast, products using formaldehyde-based adhesives release volatile organic compounds (VOCs), such as formaldehyde and phenol, during application, and these compounds are harmful to the environment and human health (Song et al. 2016). Specifically, formaldehyde was identified as a carcinogen by the International Agency for Cancer Research (IARC) in 2004. The amount of VOCs released from wooden products is severely restricted around the world. Therefore, the creation of wood adhesives based on renewable resources, simultaneously equipped with no harmful VOCs, is urgent and important for the wood industry (Wang et al. 2018).

Biomass adhesives, which have been developed in recent years, can be divided into three major categories: carbohydrates-based adhesives, natural resin-based adhesives, and protein-based adhesives. As a representative of carbohydrates-based adhesives, starchbased adhesives have many advantages because they are low cost, renewable, non-toxic, and pollution-free. However, the low bond strength and poor water resistance of starch- 
based adhesives limit their application (Imam et al. 2001). Natural resin includes lignin, shellac, rosin, and tannin. Zhang et al. (2016) prepared a lignin-furfural adhesive by hydrolyzing lignin, which is a by-product of the pulp and paper industry. However, natural resin, such as lignin, came from different raw materials and exhibited a different molecular structure, and the related studies are not sufficient. At present, the main material of a protein adhesive consists of animal protein and vegetable protein. The most important representative is soy protein-based adhesives. In general, soybean protein is extracted from soybean meal, which is a by-product of edible soybean oil manufacturing and mainly used as animal feed. Its renewability and abundance make it an ideal raw material for wood adhesives (Huang and Li 2008). The amino acids in proteins consist of many active groups, such as amino $\left(-\mathrm{NH}_{2}\right)$, carboxyl $(-\mathrm{COOH})$, phenol hydroxyl $(\mathrm{Ph}-\mathrm{OH})$, and sulfhydryl $(-\mathrm{SH})$, which are beneficial to building an adhesive. Many successful adhesives based on soybean proteins have been reported. The research employed denatured treatments (Huang and Sun 2000; Zhong et al. 2002), crosslinking reactions (Lin et al. 2012; Qi et al. 2013), blending with resin (Hamarneh et al. 2010; Nordqvist et al. 2010; Gao et al. 2012; Cheng et al. 2013; Xiao et al. 2013), enzymatic modification (Kumar et al. 2004), and constructing phenol and protein systems. However, soy is a global staple food, which means that it must be able to meet global edible demand as well as adhesive manufacturing demand, and this is related to food security. Moreover, there are properties of soybean protein adhesives that need to be improved.

Yeast hydrolysate, which is easily derived from yeast and has a high protein content, is renewable, ecofriendly, and widely available. In addition, yeast hydrolysate possesses many active groups, such as amine, carboxyl, and hydroxyl that are favorable for an adhesive. At present, yeast hydrolysate is mainly used for fodder. There has been no report that has used yeast hydrolysate for an adhesive. Compared to plant (or animal) protein, yeast hydrolysate is obtained efficiently from microorganisms that quickly grow and multiply and are free from seasonal, climatic, and regional influences. In addition, the production process is clean and environmentally friendly. The yeast hydrolysate is rich in protein, and the protein content is more than 55\%. Compared to soy protein, yeast hydrolysate contains more types and contents of amino acids. Therefore, yeast hydrolysate shows potential for a wood adhesive.

In this study, a novel wood adhesive based on yeast hydrolysate is developed by incorporating ethylene glycol diglycidyl ether (EGDE) to build an adhesive system. The deconstructed protein molecule, caused by sodium dodecyl sulfate (SDS), forms a crosslinking system with EGDE due to the ring-opening reaction between the epoxy group and the active groups (amino, carboxyl, etc.). This study also explores the influence of EGDE on the adhesive properties (density, viscosity, solid content, and bonding strength). Moreover, the curing mechanism of the adhesive is investigated using Fourier transform infrared spectrometry (FTIR) and different scanning calorimetry (DSC) analyses. As a renewable and green adhesive, this strategy can offer valuable references for the study of wood adhesives.

\section{EXPERIMENTAL}

\section{Materials}

Polyvinyl alcohol was purchased from Xiangwei Co., Ltd. (Hunan, China). Yeast hydrolysate powder with a crude protein content of $55 \%$ was purchased from Tongkai 
Biotechnology Co., Ltd. (Nanyang, China). The EGDE was purchased from Wengjiang Chemical Reagent Co., Ltd. (Guangdong, China). The SDS was purchased from Fuchen Chemical Reagent Factory (Tianjin, China). Ammonium chloride (99\%) was purchased from Fuchen Chemical Reagent Factory (Guangzhou, China). Sodium hydroxide $(99.9 \%$ purity) was purchased from Fuchen Chemical Reagent Factory (Tianjin, China). The triethylamine $(99.5 \%)$ was purchased from Pengcai Chemical Technology Co., Ltd. (Heibei, China) and potassium bromide was purchased from Beichen Fangzheng Reagent Factory (Tianjin, China). Eucalyptus (Eucalyptus saligna Smith) veneer was obtained from the Guangdong province Quality Supervision of Wood and Wood Products monitoring station (Guangzhou, China). All chemicals were analytical grade.

The following equipment was used in this study: an electronic analytical balance (AUY220; Shimadzu Corporation, Beijing, China), an electronic thermostat water bath (HH-2; Aohua Instrument Corporation, Changzhou, China), a magnetic stirring vessel (JB3A; Leici Chuangyi Instrument Corporation, Shanghai, China), a draught drying cabinet (9123A; Yiheng Instrument Corporation, Shanghai, China), a rotational viscometer (NDJ79 Lichen Technology Corporation, Zhejiang, China), a freeze drier (SCIENTZ-10N; Zhixin Biotechnology Corporation, Nìngbo, China), and a pH meter (PHS-3C; Kexiao Chemical Instrument Corporation, Hangzhou, China). The FTIR data was collected with a FTIR spectrophotometer (PerkinElmer, Inc., Shelton, CT, USA). The curing temperature change test of the yeast hydrolysate adhesive was measured using a differential scanning calorimeter (DSC200F3; NETZSCH, Bavaria, Germany). The test specimen plywood was prepared via a universal testing hot press (BY302X2/2, 150T; Xinxieli Machine Corporation, Suzhou, China). The adhesive strength was measured with a universal testing machine (AG-50KNH; Shimadzu Corporation, Beijing, China).

\section{Methods}

Preparation of the yeast hydrolysate adhesive

The yeast hydrolysate adhesive was prepared from distilled water, SDS, EGDE, polyvinyl alcohol (5\%), and yeast hydrolysate powder. The polyvinyl alcohol solution was prepared before the adhesive preparation. Then, $30 \mathrm{~g}$ polyvinyl was dissolved in $570 \mathrm{~mL}$ distilled water for $10 \mathrm{~h}$ and then stirred continuously with a glass rod for $10 \mathrm{~min}$. The adhesive was made by taking $75 \mathrm{~g}$ distilled water in a $500-\mathrm{mL}$ beaker and stirring in $100 \mathrm{~g}$ polyvinyl alcohol aqueous solution, $2 \mathrm{~g}$ SDS, and $75 \mathrm{~g}$ of protein powder. The glass rod was used to continuously stir the mixture for $10 \mathrm{~min}$ to prevent the protein powder from forming clumps. Then, the mixture was stirred for $30 \mathrm{~min}$. Finally, the EGDE was added and continuously stirred for $2 \mathrm{~h}$. All of the processes were performed at room temperature. Different adhesive groups were prepared according to the EGDE amount. The added contents of EGDE were set at $0 \%, 4 \%, 8 \%, 12 \%, 16 \%$, and $20 \%$ of the yeast hydrolysate powder amount.

\section{Apparent density determination}

The density of the yeast hydrolysate adhesive was measured according to China National Standard GB/T 14074 (2017), by using a densitometer to test the prepared adhesive (the sample was measured in an 800 - $\mathrm{mL}$ measuring cylinder), at a temperature of approximately $20^{\circ} \mathrm{C}$. Three groups were tested to calculate the average value. 


\section{Apparent viscosity}

The apparent viscosity of the yeast hydrolysate adhesive was determined according to $\mathrm{GB} / \mathrm{T} 14074$ (2017), by using a rotational viscometer with a thermostat water bath used to keep the sample at $23^{\circ} \mathrm{C}$.

\section{Solid content}

The solid content of the yeast hydrolysate adhesive was analyzed using GB/T 14074 (2017). First, the sample was placed in the drying case for $30 \mathrm{~min}$, at a temperature of approximately $20^{\circ} \mathrm{C}$, and then maintained in the dryer for $15 \mathrm{~min}$. The adhesive mass weighed $4 \mathrm{~g} \pm 0.4 \mathrm{~g}$ via an electronic balance. Afterwards, the sample was maintained for $120 \mathrm{~min}$ in the drying chamber at $120^{\circ} \mathrm{C} \pm 1{ }^{\circ} \mathrm{C}$ and then placed in the dryer for $15 \mathrm{~min}$. The ultima sample was tested in the dryer at room temperature. The value of the solid content $(C)$ was calculated according to Eq. 1,

$$
\mathrm{C}(\%)=\frac{\mathrm{m}_{3}-\mathrm{m}_{1}}{\mathrm{~m}_{2}-\mathrm{m}_{1}} \times 100
$$

where $m_{1}$ is the mass ( $\mathrm{g}$ ) of the vessel, $m_{2}$ is the weight of the sample before drying $(\mathrm{g})$, and the $m_{3}$ is the weight (g) of the sample after drying.

\section{Preparation of plywood sample and bonding strength test}

The eucalyptus veneers were pretreated in a drying kiln to maintain a temperature of $25^{\circ} \mathrm{C}$ and $10 \%$ moisture content for a week. The dimensions of the plywood samples were $320 \mathrm{~mm} \times 320 \mathrm{~mm} \times 2 \mathrm{~mm}$ (width $\times$ length $\times$ thickness). Approximately $360 \mathrm{~g} / \mathrm{m}^{2}$ of the yeast hydrolysate adhesive were brushed onto the surface of the eucalyptus wood pieces. The samples were preloaded at room temperature for $20 \mathrm{~min}$ before hot-pressing. Then, three wood pieces were layered and pressed with a hot-press at $120^{\circ} \mathrm{C}$ and $1.4 \mathrm{MPa}$ for $3 \mathrm{~min}$, the pressure reduced to $1.2 \mathrm{MPa}$ for $2 \mathrm{~min}$, and finally the pressure reduced to $0 \mathrm{MPa}$ within $5 \mathrm{~min}$. Then, the wood pieces were removed and cooled at room temperature and stored in a chamber at $25{ }^{\circ} \mathrm{C}$ and $50 \%$ relative humidity for $24 \mathrm{~h}$ for sufficient curing. Every sample was cut into the dimensions of $100 \mathrm{~mm} \times 25 \mathrm{~mm}$ (length $\times$ width) for the bonding strength test.

For the bonding strength test of the yeast hydrolysate adhesive, wood samples were measured with a universal testing machine according to GB/T 17657 (2013). The bonding strength was recorded as the stress at maximum load by a tensile machine at a speed of 1.6 $\mathrm{mm} / \mathrm{min}$.

\section{Differential scanning calorimetry}

The thermal properties of the yeast hydrolysate adhesives were analyzed by differential scanning calorimetry through a solidification process. The EGDE was added with $0 \%, 4 \%, 12 \%$, and $20 \%$ concentrations of the yeast hydrolysate powder amount. The samples were freeze-dried for $6 \mathrm{~h}$ and sealed in aluminum hermetic pans before analysis. The initial temperature of the test was $25^{\circ} \mathrm{C}$, and then heated to $220^{\circ} \mathrm{C}$ with a heating rate of $10^{\circ} \mathrm{C} / \mathrm{min}$.

\section{FTIR spectroscopy}

The adhesive samples under drying conditions at high temperatures were analyzed via Fourier transform infrared spectroscopy. The samples were oven-dried and the hotpress condition was mimicked with the same hot-press temperature and time. The samples 
were mixed with potassium bromide crystals at a weight ratio of approximately $1 / 100$ and then thoroughly ground. The FTIR data was recorded from $4000 \mathrm{~cm}^{-1}$ to $400 \mathrm{~cm}^{-1}$ with a PerkinElmer Spectrum TM 100 FTIR spectrophotometer (PerkinElmer, Inc., Shelton, CT, USA). Each sample was scanned 32 times at a resolution of $4 \mathrm{~cm}^{-1}$.

\section{RESULTS AND DISCUSSION}

\section{Apparent Density of Yeast Hydrolysate Adhesives}

Density is an elementary physical property of adhesive behaviors. The permeability of an adhesive is affected by its density. The apparent density of the yeast hydrolysate adhesives mixed with different mass fractions of EGDE is shown in Table 1. The apparent density of the protein adhesive continuously increased due to an increased EGDE content. In the absence of EGDE, the yeast hydrolysate adhesive density was $1.274 \pm 0.07 \mathrm{~g} / \mathrm{mL}$. When EGDE was added at $20 \%$ of the yeast hydrolysate powder, the density increased to $1.384 \pm 0.07 \mathrm{~g} / \mathrm{mL}$ and no changes in appearance were observed, suggesting that EGDE had no negative impact on the stability of the yeast hydrolysate-water system.

Table 1. Density, Apparent Viscosity, Solid Content, and Shear Strength of Adhesives

\begin{tabular}{|l|c|c|c|c|c|c|}
\hline & \multicolumn{6}{|c|}{ Mass Ratio of EGDE } \\
\cline { 2 - 7 } & $0 \%$ & $4 \%$ & $8 \%$ & $12 \%$ & $16 \%$ & $20 \%$ \\
\hline Density & $1.274 \pm$ & $1.281 \pm$ & $1.325 \pm$ & $1.342 \pm$ & $1.362 \pm$ & $1.384 \pm$ \\
$(\mathrm{g} / \mathrm{mL})$ & 0.07 & 0.02 & 0.01 & 0.03 & 0.06 & 0.07 \\
\hline Viscosity & $2342 \pm$ & $1930 \pm 5.5$ & $1689 \pm 12$ & $1450 \pm 15$ & $1260 \pm 10$ & $1010 \pm 5$ \\
(mPa.s) & 10.5 & & & & & \\
\hline Solid & $26.93 \pm$ & $27.35 \pm 0.5$ & $30.98 \pm 0.1$ & $31.88 \pm 0.3$ & $32.65 \pm 0.2$ & $33.84 \pm 0.3$ \\
Content & 0.2 & & & & & \\
$(\%)$ & & & & & & \\
\hline Shear & $0.4137 \pm$ & $0.5888 \pm$ & $0.6672 \pm$ & $0.8001 \pm$ & $1.0867 \pm$ & $1.2896 \pm$ \\
Strength & 0.02 & 0.03 & 0.05 & 0.03 & 0.02 & 0.03 \\
(MPa) & & & & & & \\
\hline
\end{tabular}

\section{Apparent Viscosity of Yeast Hydrolysate Adhesives}

Viscosity is an important physical property that governs the adhesive behavior of wood adhesives (Qi and Sun 2011). High viscosity adhesives are not suitable for use in the wood composite industry, whereas low viscosity adhesives easily run away from the wood or rapidly sink into it during the hot-press process (one procedure of artificial board production). Therefore, a suitable range of viscosity is important to a wood adhesive. Generally, the viscosity of a protein adhesive is high and results in decreased bonding strength. The apparent viscosity of the yeast hydrolysate adhesive was measured, and the results are shown in Table 1. Under the effect of SDS, the viscosity of the yeast hydrolysate adhesive (without EGDE) was $2342 \pm 10.5 \mathrm{mPa}$.s. This was due to a partial break in the intermolecular forces, such as electrostatic interactions or disulfide bond, between protein molecules (Xu et al. 2012).

As shown in Table 1, the viscosity of the protein adhesive decreased with an increased amount of EGDE. When the addition of EGDE was 4\% of the protein powder, the viscosity decreased from $2342 \pm 10.5 \mathrm{mPa}$.s to $1930 \pm 5.5 \mathrm{mPa} . \mathrm{s}$, a decrease of $17.5 \%$. The viscosity of the adhesive with $20 \%$ EGDE decreased to $1010 \pm 5 \mathrm{mPa}$.s, which is 
acceptable for cementing. This was because EGDE, which is a small oil molecule, could distribute in the yeast hydrolysate as a molecule lubricant to decrease the adhesive viscosity (Li et al. 2015). However, the viscosity of the yeast hydrolysate adhesive was higher than that of a common wood adhesive, and further research is needed to decrease the viscosity.

\section{Solid Content of Yeast Hydrolysate Adhesives}

The solid content of the soy protein adhesives affects performance during hot pressing (Li et al. 2004). A low solid content is undesirable for wood-based panel production. Moreover, an excess of water may lead to additional inner stress because of water vaporization, which is harmful to bonding strength (Yuan et al. 2016). However, low solid content is a common problem with protein adhesives. Table 1 shows the solid content of the yeast hydrolysate adhesives. The solid content of the adhesive without EGDE was $26.9 \% \pm 0.2$. With an addition of EGDE, the solid content continuously increased. The solid content of the adhesive with 20\% EDGE reached 33.8\%. The improvement in solid content was attributed to the addition of EGDE. Moreover, EGDE mixed well in the yeast hydrolysate adhesive system. With $25 \%$ EGDE, the solid content of the yeast hydrolysate adhesive reached a peak at $35 \%$.

\section{Shear Strength of Plywood}

The yeast hydrolysate adhesive exhibited excellent shear bonding strength under dry conditions, as shown in Table 1 . The tests were conducted according to GB/T 17657 (2013). The strength of the plywood sample prepared from the adhesive without EGDE was $0.41 \pm 0.02 \mathrm{MPa}$. The dry strength was $0.80 \pm 0.03 \mathrm{MPa}$ for the adhesive with $12 \%$ EGDE, which was higher than the specified value from GB/T 17657 (2013). The dry strength of the adhesive with $12 \%$ EGDE was $1.29 \pm 0.03 \mathrm{MPa}$, which was higher than that of commercial wood adhesives such as urea-formaldehyde resin, phenol-formaldehyde resin, and melamine-formaldehyde resin. The results indicated that the dry strength increased with the addition of EGDE. This was attributed to the ring-opening reaction that is between the epoxy group of EGDE and the active group of the yeast hydrolysate (or outer surface of wood), and which finally formed a network structure.

\section{Differential Scanning Calorimetry}

Differential scanning calorimetry is a useful tool to characterize the thermal transitions of polymers. Differences in thermal transitions are related to composition and structural changes (Liu et al. 2017). The DSC curves of yeast hydrolysate adhesives treated with different mass fractions of EGDE are shown in Fig. 1. Exothermic peaks of adhesives were in the range of $120{ }^{\circ} \mathrm{C}$ to $160{ }^{\circ} \mathrm{C}$. Although, curing reaction can be completed below $160{ }^{\circ} \mathrm{C}$. The yeast hydrolysate adhesive without EGDE (Fig. 1a) exhibited an exothermic peak at $148^{\circ} \mathrm{C}$, which can be attributed to denaturation and unfolding of yeast protein. The strong exothermic peak of the adhesive with $4 \%$ EGDE (Fig. 1b) moved to $139{ }^{\circ} \mathrm{C}$. The adhesive containing $12 \%$ EGDE showed a peak at $127^{\circ} \mathrm{C}$ (Fig. 1c). The adhesive with $20 \%$ EGDE showed a strong peak at $120{ }^{\circ} \mathrm{C}$ (Fig. 1d). These results indicated that curing temperatures gradually decreased with increased EGDE content in the adhesive. The primary cause were ascribed to reactions between the epoxy group of EGDE and the active group of the yeast hydrolysate $\left(-\mathrm{OH},-\mathrm{NH}_{2}\right.$, and $\left.-\mathrm{COOH}\right)$. 


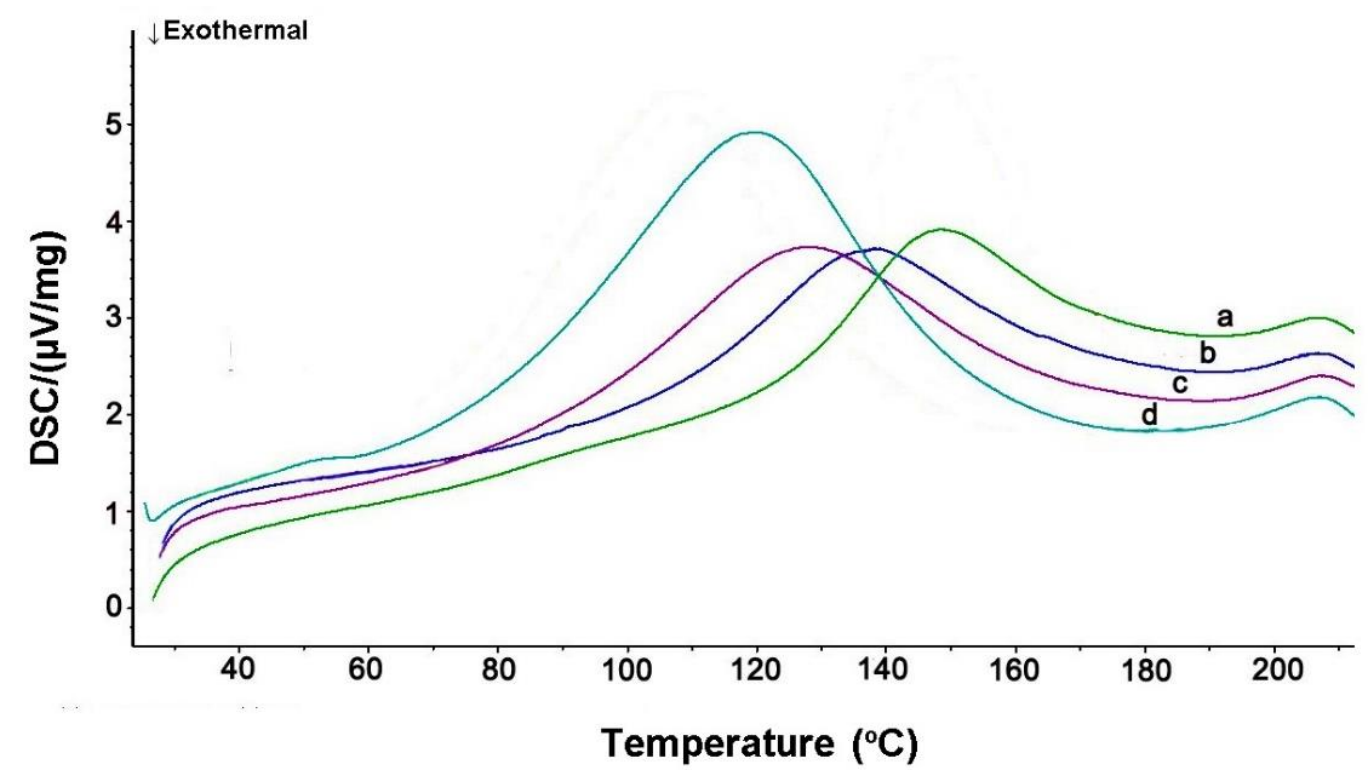

Fig. 1. DSC curves of yeast hydrolysate adhesives containing different amounts of EGDE: $0 \%$ (a), $4 \%$ (b), $12 \%$ (c), and $20 \%$ (d)

\section{FTIR Spectroscopy of Yeast Hydrolysate Adhesives}

The FTIR spectra were used to further explore changes in the molecular structure of the cured adhesives. The FTIR spectra of the cured adhesives are shown in Fig. 2.

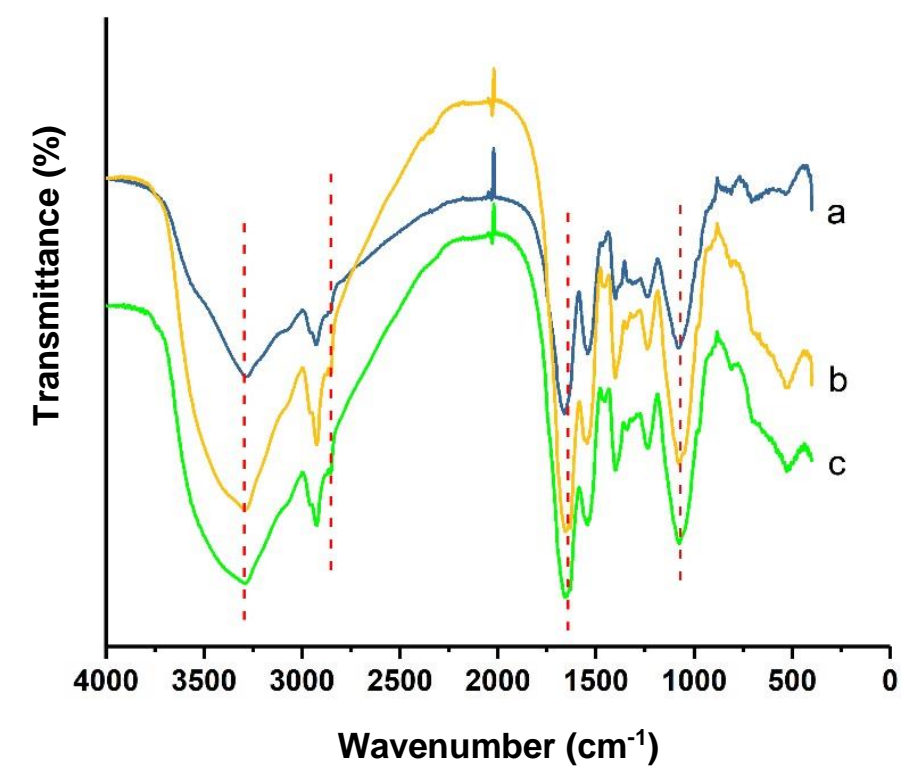

Fig. 2. The FTIR spectra of high temperature drying conditions with different mass ratios of EGDE: (a) the mass ratio of $0 \%$, (b) the mass ratio of $4 \%$, and (c) the mass ratio of $8 \%$

Yeast hydrolysate adhesives containing different amounts of EGDE were solidified under high temperature drying conditions. A peak observed at approximately $3278 \mathrm{~cm}^{-1}$ is assigned to the free bound $-\mathrm{OH}$ bending vibrations (Soares et al. 2005). Compared to the yeast hydrolysate adhesive (Fig. 2a), the EGDE-added adhesives (Fig. 2b and 2c) showed 
stronger absorption at $3278 \mathrm{~cm}^{-1}$, which suggested a larger content of -OH in the EGDEadded adhesives. Compared with adhesives without EGDE, the characteristic peaks around $2870 \mathrm{~cm}^{-1}$ of EGDE-added adhesives are more obvious, which is related to the methyl groups in proteins or lipids. The methyl group is not involved in a reaction during the curing process and be retained. It is clear that absorption peaks around $1660 \mathrm{~cm}^{-1}$ of EGDE-added adhesives are stronger than that of adhesives without EGDE. And the absorption peaks around $1660 \mathrm{~cm}^{-1}$ is caused by stretching vibration of ester bond (-COO-). This indicates that the cured EGDE-added adhesives contained more ester bond, which can have resulted from the ring-opening reaction between epoxy group and carboxyl of yeast hydrolysate. Moreover, the EGDE-added adhesives showed a stronger absorption at $1065 \mathrm{~cm}^{-1}$, which is assigned to C-O stretching (Ajuong and Redington 2004). This indicated that EGDEadded adhesives generated $\mathrm{C}-\mathrm{O}$ bonds during the curing process. The excess $-\mathrm{OH}$ group and $\mathrm{C}-\mathrm{O}$ bond were a result of the ring-opening reaction between the epoxy group of the EGDE and active group of the yeast hydrolysate (or outer surface of the wood).

\section{CONCLUSIONS}

1. A novel, renewable, and green wood adhesive was developed by combining yeast hydrolysate, sodium dodecyl sulfate (SDS), and ethylene glycol diglycidyl ether (EGDE). The results indicated that EGDE had a positive influence on the density, viscosity, solid content, bonding strength, and curing temperature of the yeast hydrolysate adhesive.

2. The differential scanning calorimetry (DSC) and Fourier transform infrared (FTIR) analyses suggested the ring-opening reaction between the epoxy group of the EGDE and the active group of the yeast hydrolysate (or outer surface of the wood) during the curing process.

3. The wood adhesive based on yeast hydrolysate offered a novel method for developing renewable and environmentally friendly wood adhesives. The results provide a valuable reference for the study of wood adhesives.

\section{ACKNOWLEDGMENTS}

The authors gratefully acknowledge the financial support by the National Key R\&D Program of China (2018YFD0600305) and the Science and Technology Project of Guangzhou, China (201803030031).

\section{REFERENCES CITED}

Ajuong, E. M. A., and Redington, M. (2004). "Fourier transform infrared analyses of bog and modern oak wood (Quercus petraea) extractives," Wood Sci. Technol. 38(3), 181-190. DOI: 10.1007/s00226-004-0236-6

Cheng, H. N., Dowd, M. K., and He, Z. (2013). "Investigation of modified cottonseed protein adhesives for wood composites," Ind. Crop. Prod. 46, 399-403. DOI: 10.1016/j.indcrop.2013.02.021 
GB/T 14074 (2017). "Testing methods for wood adhesives and their resins," Standardization Administration of China, Beijing, China.

GB/T 17657 (2013). "Test methods of evaluating the properties of wood-based panels and surface decorated wood-based panels," Standardization Administration of China, Beijing, China.

Gao, Q., Shi, S., Li, J., Liang, K., and Zhang, X. (2012). "Soybean meal-based wood adhesives enhanced by modified polyacrylic acid solution," BioResources 7(1), 946956. DOI: 10.15376/biores.7.1.0946-0956

Hamarneh, A., Heeres, H., Broekhuis, A., Sjollema, K., Zhang, Y., and Picchioni, F. (2010). "Use of soy proteins in polyketone-based wood adhesives," Int. J. Adhes. Adhes. 30(7), 626-635. DOI: 10.1016/j.ijadhadh.2010.06.002

Huang, J., and Li, K. C. (2008). "A new soy flour-based adhesive for making interior type II Plywood,” J. Am. Oil Chem. Soc. 85(1), 63-70. DOI: 10.1007/s11746-0071162-1

Huang, W., and Sun, X. (2000). "Adhesive properties of soy proteins modified by urea and guanidine hydrochloride," J. Am. Oil Chem. Soc. 77(1), 101-104. DOI: 10.1007/s11746-000-0016-6

Imam, S. H., Gordon, S. H., Mao, L., and Chen, L. (2001). "Environmentally friendly wood adhesive from a renewable plant polymer: Characteristics and optimization," Polym. Degrad. Stabil. 73(3), 529-533. DOI: 10.1016/S0141-3910(01)00114-8

Kumar, R., Choudhary, V., Mishra, S., and Varma, I. (2004). "Enzymatically modified soy protein part 2: Adhesion behavior," J. Adhes. Sci. Technol. 18(2), 261-273. DOI: $10.1163 / 156856104772759458$

Li, J., Luo, J., Li, X., Yi, Z., Gao, Q., and Li, J. (2015). "Soybean meal-based wood adhesive enhanced by ethylene glycol diglycidyl ether and diethylenetriamine," Ind. Crop. Prod. 74, 613-618. DOI: 10.1016/j.indcrop.2015.05.066

Li, K., Peshkova, S., and Geng, X. (2004). "Investigation of soy protein-kymene adhesive systems for wood composites," J. Am. Oil Chem. Soc. 81(5), 487-491. DOI: 10.1007/s11746-004-0928-1

Lin, Q., Chen, N., Bian, L., and Fan, M. (2012). "Development and mechanism characterization of high performance soy-based bio-adhesives," Int. J. Adhes. Adhes. 34, 11-16. DOI: 10.1016/j.ijadhadh.2012.01.005

Liu, H., Li, C., and Sun, X. S. (2017). "Soy-oil-based waterborne polyurethane improved wet strength of soy protein adhesives on wood," Int. J. Adhes. Adhes. 73, 66-74. DOI: 10.1016/j.ijadhadh.2016.09.006

Nordqvist, P., Khabbaz, F., and Malmström, E. (2010). "Comparing bond strength and water resistance of alkali-modified soy protein isolate and wheat gluten adhesives," Int. J. Adhes. Adhes. 30(2), 72-79. DOI: 10.1016/j.ijadhadh.2009.09.002

Pradyawong, S., Qi, G., Li, N., Sun, X. S., and Wang, D. (2017). "Adhesion properties of soy protein adhesives enhanced by biomass lignin," Int. J. Adhes. Adhes. 75, 66-73. DOI: 10.1016/j.ijadhadh.2017.02.017

Qi, G., Li, N., Wang, D., and Sun, X. (2013). "Physicochemical properties of soy protein adhesives modified by 2-octen-1-ylsuccinic anhydride," Ind. Crop. Prod. 46, 165172. DOI: 10.1016/j.indcrop.2013.01.024

Qi, G., and Sun, X. S. (2011). "Soy protein adhesive blends with synthetic latex on wood veneer," J. Am. Oil Chem. Soc. 88(2), 271-281. DOI: 10.1007/s11746-010-1666-y 
Soares, R. M. D., Scremin, F. F., and Soldi, V. (2005). "Thermal stability of biodegradable films based on soy protein and corn starch," Macromol. Symp. 229(1), 258-265. DOI: 10.1002/masy.200551132

Song, Y. H., Seo, J. H., Choi, Y. S., Kim, D. H., Choi, B., and Cha, H. J. (2016). "Mussel adhesive protein as an environmentally-friendly harmless wood furniture adhesive," Int. J. Adhes. Adhes. 70, 260-264. DOI: 10.1016/j.ijadhadh.2016.07.008

Wang, F., Wang, J., Chu, F., Wang, C., Jin, C., Wang, S., and Pang, J. (2018). "Combinations of soy protein and polyacrylate emulsions as wood adhesives," Int. J. Adhes. Adhes. 82, 160-165. DOI: 10.1016/j.ijadhadh.2018.01.002

Xiao, Z., Li, H., Wu, X., Qi, G., Li, N., Zhang, K., Wang, D., and Sun, X. S. (2013). "Utilization of sorghum lignin to improve adhesion strength of soy protein adhesives on wood veneer," Ind. Crop. Prod. 50, 501-509. DOI: 10.1016/j.indcrop.2013.07.057

$\mathrm{Xu}$, H., Shen, Q., Ouyang, X., and Yang, L. (2012). "Wetting of soy protein adhesives modified by urea on wood surfaces," Eur. J. Wood Wood Prod. 70(1-3), 11-16. DOI: 10.1007/s00107-010-0502-2

Yuan, C., Luo, J., Luo, J., Gao, Q., and Li, J. (2016). “A soybean meal-based wood adhesive improved by a diethylene glycol diglycidyl ether: Properties and performance," RSC Adv. 6(78), 74186-74194. DOI: 10.1039/c6ra07844c

Zhang, Y., Yuan, Z., Mahmood, N., Huang, S., and Xu, C. C. (2016). "Sustainable biophenol-hydroxymethylfurfural resins using phenolated de-polymerized hydrolysis lignin and their application in bio-composites," Ind. Crop. Prod. 79, 84-90. DOI: 10.1016/j.indcrop.2015.10.048

Zhong, Z., Sun, X. S., Fang, X., and Ratto, J. A. (2002). "Adhesive strength of guanidine hydrochloride-modified protein for fiberboard application," Int. J. Adhes. Adhes. 22(4), 267-272. DOI: 10.1016/S0143-7496(02)00003-9

Article submitted: November 22, 2018; Peer review completed: March 16, 2019; Revised version received: April 13, 2019; Accepted: May 18, 2019; Published: June 12, 2019. DOI: $10.15376 /$ biores.14.3.6015-6024 